\title{
ZWISCHEN REALITÄT UND MYTHOS. TOD UND BEGRÄBNISSE VON PROFESSOREN DER PRAGER UNIVERSITÄT VOM 15. BIS ZUM FRÜHEN 17. JAHRHUNDERT
}

\author{
MLADA HOLÁ - MARTIN HOLÝ
}

\begin{abstract}
BETWEEN REALITY AND MYTH. THE DEATH AND FUNERALS OF PROFESSORS OF THE UNIVERSITY OF PRAGUE FROM THE 15TH TO THE BEGINNING OF THE 17TH CENTURY
\end{abstract}

The study focuses on questions relating to the deaths of professors of the Utraquist university in Prague from the late fifteenth century to the early seventeenth century (cause of death, funerals, estates, forms and means of commemoration, etc.). It is based on sources of official provenance as well as on certain egodocuments and literary, iconographic, and material sources. Because from the Middle Ages they most commonly served as the final resting places of university masters, attention is also devoted to the Corpus Christi Chapel in New Town, Prague, and the Bethlehem Chapel in Old Town, Prague.

Keywords: University of Prague - professors - funeral culture - Late Middle Ages - early modern period

DOI: $10.14712 / 23365730.2020 .22$

Das Sterben, der Tod und die Begräbniskultur der vormodernen Zeit als Ganzes gehören zu jenen Themen der Kulturgeschichte, die erst in der zweiten Hälfte des 20. Jahrhunderts einen deutlichen Aufschwung verzeichneten. Eine zentrale Rolle kam dabei den Arbeiten $\mathrm{zu}$, die im Rahmen der französischen Annales-Schule entstanden. Diese haben nicht nur die Forschung in weiteren Ländern des europäischen Kontinents, sondern auch in der angelsächsischen Welt geprägt. Es sind zahlreiche Monografien zu Teilthemen sowie einige wertvolle Versuche einer synthetischen Aufarbeitung entstanden. In der tschechischen Historiografie wurde trotz älteren Anfängen diesem Thema erst ab den achtziger Jahren des 20. Jahrhunderts größere Aufmerksamkeit gewidmet. ${ }^{1}$

1 Vgl. zumindest Pierre Chaunu, La Mort à Paris, XVIe, XVIIe, XVIIIe siècles, Paris 1978; Norbert Ohler, Sterben und Tod im Mittelalter, München 1990; Philippe Ariès, Geschichte des Todes, 7. Aufl., München 1995; Pavel KRÁL, Smrt a pohřby české šlechty na počátku novověku [Tod und Begräbnisse zu Beginn der Neuzeit], České Budějovice 2004; Martin Holý - Jiří MikuleC (edd.), Církev a smrt: institucionalizace smrti v raném novověku [Die Kirche und der Tod: Institutionalisierung des Todes in der Frühen Neuzeit], Praha 2007; Radmila PavlíčKová, Triumphus in mortem. Pohřebni kázání nad biskupy v raném novověku [Triumphus in mortem. Leichenpredigten zu Bischöfen in der Frühen Neuzeit], České Budějovice 2008; Tomáš MalÝ, Smrt a spása mezi Tridentinem a sekularizací (brněnští měštané a proměny laické zbožnosti v 17. a 18. století) [Tod und Heil zwischen Tridentinum und Säkularisierung (die Brünner Bürger und der Wandel der Laienfrömmigkeit im 17. und 18. Jahrhundert], Brno 2009; Václav BủžEK - Pavel MareK, Smrt Rudolfa II. [Der Tod Rudolfs II.], Praha 2015. 
Eine eigenständige Position im Rahmen dieser Forschung hat die mit dem akademischen Milieu verbundene Funeralkultur inne. Sie gehört, auch im europäischen Kontext, zu den nur wenig aufgearbeiteten Themen - sei es nun die relativ hohe Mortalität der Schüler von Lateinschulen oder aber der Studierenden an damaligen Universitäten sowie ihrer Lehrer. Bis auf eine gewisse Ausnahme, die Arbeiten von Zikmund Winter und einige weitere Studien zu Einzelpersonen bzw. zu gewissen spezifischen Themen, z. B. Grabsteinen, ${ }^{2}$ betreffen, erfuhr die Prager Universität in dieser Hinsicht bislang keine systematische Aufmerksamkeit. Der vorliegende Beitrag wird also versuchen, einige Möglichkeiten dieses Forschungsbereiches anzudeuten und zugleich auf dessen enge Verknüpfung mit der Erforschung der Erinnerungskultur und dem Entstehen der kollektiven Erinnerung und der kollektiven Identität im Umfeld der Prager Universität zwischen dem 15. und dem frühen 17. Jahrhundert hinzuweisen.

Was die Quellenbasis anbelangt, kann bei der Analyse der erwähnten Zusammenhänge einerseits von amtlichen Quellen, andererseits von einigen Ego-Dokumenten, literarischen, ikonografischen und materiellen Quellen ausgegangen werden. ${ }^{3}$ In der Frühen Neuzeit nimmt deren Anzahl deutlich zu, und zwar nicht nur infolge der steigenden Bedeutung der Verschriftlichung und der allgemeinen Bürokratisierung, sondern auch wegen der Durchsetzung des Buchdrucks und des Humanismus, die sich im Zusammenhang mit unserem Thema u. a. in der Herausgabe von humanistischer Gelegenheitspoesie und von Leichenpredigten niederschlug. ${ }^{4}$ Auch die übrigen Quellenarten sind viel besser aus der Frühen Neuzeit überliefert. Einige Prozesse, die sich während des 18. und 19. Jahrhunderts Bahn brachen, führten hingegen zum Verlust der Erinnerung: beispielsweise die Auflösung und der Abriss einiger Prager Kirchen, in denen die Gebeine von Professoren ruhten. ${ }^{5}$

Das Maß an Kenntnissen über ungefähr 200 Personen, die während der zweiten Hälfte des 15. Jahrhunderts bis 1622 an der Prager Universität als ordentliche Professoren (magistri actu regentes, professores ordinarii) tätig waren, ist sehr unausgewogen. Über viele von ihnen haben wir nur bruchstückhafte Informationen. Nichtsdestotrotz stehen bei vielen von ihnen Informationen über ihr Sterben, die Todesursache sowie über weitere mit dem Tod zusammenhängende Umstände zur Verfügung. Angesichts ihrer Unvollständigkeit in Bezug auf die Funeralkultur können sie jedoch nicht statistisch ausgewertet werden, nicht einmal für die quellenmäßig besser dokumentierte Frühe Neuzeit. ${ }^{6}$

2 Zikmund WinTER, O životě na vysokých školách pražských knihy dvoje [Zwei Bücher über das Leben an den Prager Hochschulen], Praha 1899; Bohumil RYвA, Epitafy v kapli Betlémské [Epitaphe in der Bethlehemskapelle], Věstník Královské české společnosti nauk - Tř́ída filosoficko-historicko-filologická, 1951, IV, Praha 1952.

3 Konkrete Beispiele werden in weiteren Anmerkungen angeführt.

4 Vgl. vor allem Josef HeJNIC - Jan MARTíNEK, Rukovět’ humanistického básnictví v Čechách a na Moravě. Enchiridion renatae poesis Latinae in Bohemia et Moravia cultae, I-VI, [Vademecum der humanistischen Dichtung in Böhmen und Mähren I-VI] (weiter zitiert als Enchiridion), Praha 1966-2011. Manche Texte dieses Typus' sind auch in folgender Datenbank registriert: <www.knihopis.cz>. Zur Prager utraquistischen Universität vgl. Z. WINTER, O životě na vysokých školách pražských, S. 206f. Zum literarischen Umfeld dieser Universität vgl. ebenfalls Lucie Storchová, Paupertate styloque connecti: utvárenei humanistické učenecké komunity v českých zemich [Paupertate styloque connecti: von der Herausbildung der humanistischen Gelehrtengemeinschaft in den böhmischen Ländern], Praha 2011.

5 Konkrete Literatur- und Quellenhinweise vgl. weiter unten.

6 Daten zu Professoren der Prager Universität, die wir in unserer Analyse nutzen, beinhaltet u. a. die Datenbank, die im Rahmen des Projektes Universitas magistrorum. Professors of Prague Utraquist University (1458-1622) entstand und über die in der Studie von Jana Borovičková und Jaroslava Škudrnová in dieser Zeitschrift ausführlich informiert wird. Die Datenbank ist noch nicht öffentlich zugänglich. 
Obwohl es in der Regel an detaillierten quellenbasierten Informationen mangelt, kann auch bei den Professoren der Prager Universität erwartet werden, dass sie danach strebten, das Ideal des sogenannten guten Todes zu erfüllen, das dem utraquistischen Milieu entsprach, dem die meisten der untersuchten Personen angehörten. Einige von ihnen waren aber auch Lutheraner oder Angehörige der Brüderunität. In diesen Fällen konnten die funeralen Gepflogenheiten abweichen. Entscheidend war natürlich auch, unter welchen Umständen und wo der Tod eintrat.

Die meisten der betrachteten Personen starben - wenn sie nicht ihre universitäre Karriere aufgaben, was recht üblich war - in einem der Magisterkollegs, in denen sie wohnten, also im Karlskolleg, dem Kolleg König Wenzels und dem Allerheiligenkolleg, die sich allesamt in der Prager Altstadt befanden. ${ }^{7}$ Einige Professoren der Prager Universität hatten jedoch zum Zeitpunkt ihres Todes auch ein Amt inne, das sie dazu berechtigte, sich langfristig woanders aufzuhalten, und somit können sie an diesem anderen Ort gestorben sein, beispielsweise im Prager Slawenkloster, zu dessen Äbten einige von ihnen zählten. ${ }^{8}$

Bei lang andauernden Gesundheitsproblemen konnten die Magister aus dem Kolleg ausgezogen sein und offenbar bessere Pflege und ein passenderes Umfeld beispielsweise in einem der Häuser in der Prager Altstadt gefunden haben (so starb z. B. 1517 Paul von Saaz in dem Haus von Wenzel Pikart, in das er umgezogen war). ${ }^{9}$ Schließlich konnten die Professoren nach der Aufhebung des Zölibats und der Einführung der Möglichkeit, parallel auch eine andere Karriere zu verfolgen, nach dem Erlass des Majestätsbriefes Rudolfs II. über

7 Vgl. zumindest: Alois KuBIČEK - Alena PetrÁŇOvÁ - Josef PetráŇ, Karolinum a historické koleje University Karlovy v Praze [Das Karolinum und die historischen Kollegs der Karlsuniversität in Prag], Praha 1961; Michal Svatoš, Kolej krále Václava pražské univerzity [Das König-Wenzel-Kolleg der Prager Universität], Památky a prŕroda 5, 1977, S. 257-262; Ders., Hospodářské zázemi pražské univerzity v době Karla IV. (1347-1378) [Die wirtschaftliche Grundlage der Prager Universität in der Zeit Karls IV. (1347-1378)], Acta Universitatis Carolinae - Historia Universitatis Carolinae Pragensis (weiter AUC-HUCP) 18/2, 1978, S. 7-36, hier S. 9f. und 18-20; Ders., Pražská univerzitni kolej Všech svatých [Das Prager Universitätskolleg zu Allerheiligen], AUC-HUCP 31/1, 1991, S. 85-93; František ŠMAHEL, Die Prager Universität im Mittelalter - The Charles University in the Middle Ages. Gesammelte Aufsätze - Selected Studies, Leiden - Boston 2007, S. 89; Eric Wolfgang Wagner, Universitätsstift und Kollegium in Prag, Wien und Heidelberg. Eine vergleichende Untersuchung spätmittelalterlicher Stiftungen im Spannungsfeld von Herrschaft und Genossenschaft (Europa im Mittelalter 2), Berlin 1999; Josef PetráŇ, Karolinum, Prague 2010; František Šmahel, Alma mater Pragensis. Studie k počátki̊m Univerzity Karlovy [Alma mater Pragensis. Eine Studie zu den Anfängen der Karlsuniversität], Praha 2016, S. 26, 47, 94; Mlada HolÁ - Martin Holý, Das Prager Karlskolleg im Spätmittelalter und in der Frühen Neuzeit als Ort der universitären Wissensvermittlung (1436-1622), in: Angelika Kemper (Hg.), Zwischen Himmel und Alltag. Wissen und Gemeinschaft vom Hochmittelalter bis in die Frühe Neuzeit (im Druck). Vgl. ebenfalls Peter Moraw, Die Universität Prag im Mittelalter. Grundzüge ihrer Geschichte im europäischen Zusammenhang, in: Die Universität zu Prag (Schriften der Sudetendeutschen Akademie der Wissenschaften und Künste 7), München 1986, S. 9-134; Ders., Die Prager Universitäten des Mittelalters, in: Susanne Burghartz (Hg.), Spannungen und Widersprüche. Gedenkschrift für František Graus, Sigmaringen 1992, S. 109-123.

8 Zum Beispiel Matthias Corambus $(\uparrow 1536)$ und Heinrich Curius $(\dagger 1582)$.

9 Josef Teige, Základy starého mistopisu Pražského (1437-1620), I, Staré Město pražské 2 [Grundlagen der alten Prager Topographie (1437-1620), I, Die Prager Altstadt 2], Praha 1915, S. $790 \mathrm{f}$. 
die Religionsfreiheit 1609 selbst Bürgerhäuser besitzen..$^{10}$ Andere verstarben auf Reisen. ${ }^{11}$ Sehr spezifisch sind die Umstände des Todes von Sigismund Antoch von Helfenberg, der 1552 von Wenzel von Kolovrat ermordet wurde, ${ }^{12}$ oder des einstigen Rektors der Prager Universität und berühmten Arztes Johannes Jessenius. Er wurde nach der Niederlage des Ständeaufstands von 1618-1620 am 21. Juni 1621 auf dem Prager Altstädter Ring hingerichtet, und seine sterblichen Überreste wurden zur Abschreckung auf dem Altstädter Brückenturm ausgestellt. ${ }^{13}$

Um kranke Professoren, bei denen das Ende ihres irdischen Daseins nahte, kümmerten sich in ihren Wohnungen in der Regel ihre Köchinnen bzw. Famuli. ${ }^{14} \mathrm{Zu}$ erwarten ist auch ärztliche Hilfe beziehungsweise die Zurverfügungstellung einer weiteren Person, die sie pflegte. In einem Fall ist die Pflege durch eine direkte Verwandte belegt (im Falle des Professors und langjährigen Rektors Peter Codicillus). ${ }^{15}$ Die Ursachen des Todes, der in unterschiedlichem Alter eintrat und die wir nur in einer begrenzten Anzahl von Fällen kennen, und auch dann nicht immer ganz eindeutig, waren sehr verschieden. Neben Begleiterscheinungen des Alters waren es Pestepidemien, von denen Prag im untersuchten Zeitraum regelmäßig heimgesucht wurde, Schlaganfälle, Herzversagen, schwere neurologische oder dermatologische Erkrankungen sowie tödliche Unfälle, die auch durch Trunkenheit verursacht werden konnten.

10 Das gilt z. B. für Adam Huber von Riesenpach, langjähriger Professor der Prager Universität und ihr Rektor (1612/1613), der ein Haus in der Prager Neustadt besaß, in welchem er auch vor seinem Tod wohnte. Er starb am 23. Juni 1613 und wurde anschließend in der St.-Heinrich-Kirche (in der Nähe seines Hauses) beigesetzt. Die Universität und ihre Mitglieder nahmen an den Begräbnisfeierlichkeiten teil. Zu H. von Riesenpach vgl. vor allem seine Biogramme in Enchiridion II, S. 364ff., und Martin HolÝ, Ve službách šlechty. Vychovatelé nobility z českých zemí (1500-1620) [Im Dienste des Adels. Erzieher von Adeligen aus den böhmischen Ländern (1500-1620)], Praha 2011, S. 195f. (in beiden Fällen mit weiteren Verweisen).

11 Martin von Klattau ist beispielsweise in seinem Geburtsort (Klattau) 1555 gestorben, Georg Sušil während der Pestepidemie 1582 in Saaz.

12 Marcus Bydzovinus, Collectanea, Nationalbibliothek der Tschechischen Republik Prag (weiter als NB Prag), Sign. XXIII D 217, Fol. 34r-v, 39r-40r, 43v-44r; Z. WINTER, O životě na vysokých školách pražských, S. 90f., 152; Lothar Schletz, Die Magister der artistischen Fakultät der Hohen Schule zu Prag und ihre Schriften im Zeitraum von 1409 bis 1550, Erlangen - Nürnberg 1971, S. 96; František ŠMAHEL - Gabriel SiLAGI (edd.), Statuta et acta rectorum Universitatis Carolinae Pragensis 1360-1614 (Documenta Historica Universitatis Carolinae Pragensis 1), Praha 2018, S. 118.

13 Zu Jessenius vgl. Friedl PICK, Johann Jessenius de Magna Iessen, Leipzig 1926; Josef PoLišEnskÝ, K politické činnosti Jana Jesenského-Jessenia [Zur politischen Tätigkeit von Johann Jesenský-Jessenius], AUC-HUCP 2/2, 1961, S. 87-128; Ders., Jan Jesenský-Jessenius, Praha 1965; Enchiridion II, S. 439ff.; Tomáš NeJESCHLEBA, Jan Jesenský v kontextu renesanční filosofie [Johann Jessenius im Kontext der Philosophie der Renaissance], Praha 2008. Über seine Hinrichtung berichtet Johann Amos Comenius, Historie o těžkých protivenstvích cirkve české [Geschichte der schweren Widernisse der böhmischen Kirche], Praha 1902, S. 194-197; Margot Lindemann, Johannes Jessenius und die Prager Exekution von 1621, Jahrbuch der Schlesischen Friedrich Wilhelms-Universität zu Breslau 6, 1961, S. 351-368. Zur Situation der Karlsuniversität nach der Schlacht am Weißen Berg vgl. bis heute am ausführlichsten Zikmund WINTER, Děje vysokých škol pražských od secessí cizich národi̊ po dobu bitvy bélohorské (1409-1622) [Geschichte der Prager Hohen Schulen vom Auszug der fremden Nationen bis zur Schlacht am Weißen Berg (1409-1622)], Praha 1897, S. 162-216. Vgl. ebenfalls František KavkA - Josef Petrán̆ (eds.), A History of Charles University, I, 1348-1802, Prague 2001, S. 263-297 (Autorin des Kapitels The Administrative and Institutional Development of Prague University ist Ivana ČORNEJOVÁ).

14 Z. WinTER, O životě na vysokých školách, S. 202f.

15 Archiv der Hauptstadt Prag, Handschrift 1122, Fol. 162r, 163v; Z. WinTER, O životě na vysokých školách, S. 202. Zu Peter Codicillus (1533-1589) vgl. zumindest Enchiridion I, S. 389-402; M. Holý, Ve službách šlechty, S. 208f., und Jiří Pešek in diesem Band. 
Nach dem Tod, vor dem üblicherweise ein Testament niedergeschrieben worden war, ${ }^{16}$ folgte die Versiegelung der Wohnung des verstorbenen Professors und eine Inventarisierung seines Vermögens, seiner beweglichen bzw. auch der unbeweglichen Güter durch den Probst des jeweiligen Kollegs unter Anwesenheit von Magistern und hinzugezogenen Zeugen. Nichtsdestotrotz kam es bereits vor der Inventarisierung zu verschiedenen Diebstählen. ${ }^{17}$ In das Verzeichnis wurden auch eventuelle Schulden oder aber Forderungen des Professors aufgenommen. Zur Abrechnung gehörten ebenfalls die Begräbniskosten. ${ }^{18}$ Die darauffolgenden Nachlassverfahren waren nicht selten von Streitigkeiten zwischen der Universität und den Verwandten der Verstorbenen begleitet, die oft verschiedene Verfügungen im Testament oder die Korrektheit der Inventarisierung in Zweifel zogen. Auch hier waren zahlreiche Umstände im Spiel, auf die wir hier nicht näher eingehen können. ${ }^{19}$

Die überlieferten Quellen belegen leider nicht, was nach dem Tode des Professors mit seinem Leichnam geschah. Die Zeit, die zwischen Tod und Begräbnis verging, hing unter anderem von der Todesursache ab. Wenn es die Pest war oder die Pest zumindest dafür gehalten wurde, fand das Begräbnis meistens unmittelbar nach dem Tode statt. Aber auch wenn dies nicht der Fall gewesen war, war dieser Zeitraum zumeist nicht sehr lang. In der Regel betrug er nur einige wenige Tage, die für die Vorbereitung des Begräbnisses notwendig waren. Wir verfügen hier nur über sehr wenige Informationen.

Der Tod selbst sowie die Abhaltung des Begräbnisses wurden in der Frühen Neuzeit den Angehörigen der Universität sowie der breiteren Öffentlichkeit durch sogenannte Intimationen, also Bekanntmachungen des Rektors oder des Dekans der Artistischen Fakultät mitgeteilt, die oft an die Tür des Karolinums angebracht wurden. Meistens geschah dies am ersten Tag nach dem Ableben des Professors. Die Intimationen enthielten unter anderem die Information über den Todestag und eine Zusammenfassung der wichtigsten biografischen Daten des Verstorbenen mit Betonung seiner Verdienste um die Universität. Auch Tag und Uhrzeit des Begräbnisses, das zumeist bereits am Tage nach dem Tod stattfand, wurden darin bekanntgegeben. Intimationen wurden auch in einigen Fällen beim Ableben ehemaliger Professoren der Karlsuniversität ausgehängt. ${ }^{20}$

16 Wir haben viele solcher Testamente, auf die aber wegen ihrer Anzahl hier nicht im einzelnen verwiesen werden kann. Die meisten sind in Prager Stadtbüchern registriert, andere befinden sich aber auch anderswo (z. B. in Städten, in denen die Professoren ihr Vermögen hatten). Das Liber memorabilium der Karlsuniversität selbst ist leider nicht überliefert.

17 Vgl. z. B. zur Inventarisierung der Sachen nach dem Tode von Professor Johann Adami von Bystritz († 1602) oder Johannes Gottsmannius $(\dagger 1606)$ : Archiv der Karlsuniversität (weiter zitiert als AKU), Sign. Oec. B 14, 188r; ebd., Oec. Sign. B18, Fol. 335r-v; Z. WINTER, O životě na vysokých školách, S. 203, 209.

18 Zum Beispiel B. AKU, Sign. B 14, Fol. 188r, 201v-204v, 214r-v; ebd., Sign. B 24, Fol. 130r, 132r.

19 Vgl. dazu Z. WinTer, O životě na vysokých školách, S. $209 \mathrm{f}$.

20 Die meisten erhaltenen Texte der sogenannten Intimationen kennen wir dank der Abschriften von Markus Bydschovinus in der als Collectanea bezeichneten und schon oben erwähnten Handschrift - NB Prag, Sign. XXIII D 217, passim. Vgl. ebenfalls Z. WINTER, O životě na vysokých školách, S. 205f. In einigen Fällen wird der Tod der Professoren auch in Briefen erwähnt. So hat z. B. der Universitätsrektor am Tag des Begräbnisses von Johannes Chorinnus ein Schreiben nach Hermannstädtel geschickt, in dem er einen neuen Schulverwalter (Simeon Christophorides) ernennt und zugleich die Verdienste von Chorinnus um die dortige Schule betont; František Dvorský (ed.), Paměti o školách českých. Listář školství českého v Čechách a na Moravě od l. 1598 do 1616 s doklady starši i pozdějši doby [Denkwürdigkeiten zu böhmischen Schulen. Dokumente des böhmischen Schulwesens in Böhmen und Mähren von 1598 bis 1616 mit Belegen der älteren und späteren Zeit], Praha 1886, Nr. 377, S. 288. 
Der Verlauf der Begräbnisse und die konkrete letzte Ruhestätte für verstorbene Angehörige der Prager Universität hingen von verschiedenen Umständen ab - unter anderem vom Wunsch des Verstorbenen selbst, der auch in seinem Testament geäußert sein konnte. Als die am häufigsten verwendeten letzten Ruhestätten setzten sich bereits im Mittelalter vor allem zwei Orte durch, nämlich die Fronleichnamskapelle in der Prager Neustadt und die Bethlehemskapelle in der Prager Altstadt.

Die Fronleichnamskapelle wurde zwischen 1382 und 1393 inmitten des damaligen Viehmarkts (heute der Platz Karlovo náměstí) gebaut. Ihr Vorgänger war offenbar ein Holzturm gewesen, von dem aus unter Karl IV. am Fest der heiligen Lanze und der Nägel vom Kreuz des Herrn (am Freitag nach der Osteroktav) die zum Reichskrönungsschatz gehörenden heiligen Reliquien gewiesen wurden. Über der Mitte des Baus stand ein massiver quadratischer Turm. Der Grundriss hatte aller Wahrscheinlichkeit nach die Form eines griechischen Kreuzes, zwischen dessen Seiten offenbar weitere Kapellen eingeschoben waren. $\mathrm{Ab}$ dem Spätmittelalter führten Fronleichnamsprozessionen dorthin. Im Jahre 1403 wurde die Kapelle der Verwaltung durch die Prager Universität bzw. durch die böhmische Universitätsnation anvertraut. Der Landesherr behielt hier aber weiterhin das Patronatsrecht. ${ }^{21}$

Obwohl die Universitätsmagister bereits während des Spätmittelalters in der Fronleichnamskapelle bestattet wurden, stehen mehrere Belege erst für das 16. und das frühe 17. Jahrhundert zur Verfügung, als hier viele von ihnen ihre letzte Ruhestätte fanden, und zwar bis zur Übernahme der Karlsuniversität und somit auch ihrer Kapelle Corporis Christi durch die Jesuiten im Jahre 1622. Die Fronleichnamskapelle, die unter Joseph II. aufgehoben und danach abgerissen wurde, spielte auch eine zentrale Rolle als Ort gesungener Vigilien für die Seelen von Wohltätern der Universität sowie von einstigen Professoren. Diese Vigilien sind in den Quellen bereits ab den sechziger Jahren des 15. Jahrhunderts belegt. Die Teilnahme daran war, ebenso wie die Beteiligung an den Begräbnissen, für alle Angehörigen der Universität unter Androhung von Geldbußen obligatorisch. ${ }^{22}$

Als zweithäufigster Bestattungsort der Professoren setzte sich ebenfalls bereits während des Spätmittelalters die Bethlehemskapelle durch. Sie wurde 1391 für tschechische Predigten gegründet, insbesondere dank der Bemühungen Hanuš’ von Mühlheim und des Altstädter Krämers Kříž. Die Kapelle wurde jahrhundertelang vor allem mit der Tätigkeit von Magister Jan Hus assoziiert, der hier in den Jahren 1402-1413 predigte und ebenfalls Professor und Rektor der Karlsuniversität war. Auch deshalb war sie ein beliebter Ort für

21 Zusammenfassend Miloslav Polívka, K širreni husitství v Praze (Bratrstvo a kaple Božiho těla na Novém Městě pražském v předhusitské době) [Zur Verbreitung des Hussitentums in Prag (Die Fronleichnamsbruderschaft und -kapelle in der Prager Neustadt in vorhussitischer Zeit)], Folia Historica Bohemica 5, 1983, S. 95-118. Vgl. ebenfalls mit weiteren Verweisen Hana Pátкové, Bratrstva ke cti Božie. Poznámky ke kultovní ćinnosti bratrstev a cechĩ ve středověkých Čechách [Bruderschaften zu Ehren Gottes. Notizen zur Kulttätigkeit der Bruderschaften und Zünfte im mittelalterlichen Böhmen], Praha 2006, S. 16, 118; Blanka ZiLYNSKÁ, Pražská univerzita - patron církevních beneficií? [Die Prager Universität - Patron von Kirchenbenefizien?], AUCHUCP 47/1-2, 2007, S. 75-87, hier S. 83; Mlada HoLÁ, Studentské koleje pražské univerzity v pozdním středovéku a raném novověku. Déjiny - správa - úredni pisemnosti (do roku 1622) [Studentenkollegs der Prager Universität im Spätmittelalter und in der Frühen Neuzeit. Geschichte - Verwaltung - amtliche Schriftstücke (bis 1622)], Praha 2018, S. 74-78; Jan Hrdina, Kaple Božího Těla na Novém Městě pražském v době préedhusitské - dvě drobné sondy [Die Fronleichnamskapelle in der Prager Neustadt in vorhussitischer Zeit - zwei kleine Sonden], Staletá Praha 29/2, 2013, S. 21-38; Ota Halama, Osudy kaple Božiho Těla po roce 1437 [Das Schicksal der Fronleichnamskapelle nach 1437], Staletá Praha 29/2, 2013, S. 39-49.

22 Antonius DitTrich - Antonius SPIRK (edd.), Monumenta historica Universitatis Pragensis, III, Statuta Universitatis Pragensis nunc primum publici juris facta, Pragae s. d., S. 235f.; NB Prag, Sign. XXIII D 217, Fol. 12 v. 
Begräbnisse von Vertretern sozialer Eliten der Stadt und des Adels. Die Bethlehemskapelle, die eng mit dem studentischen Nazareth-Kolleg verbunden war, wurde während der Frühen Neuzeit von der Universität verwaltet, die auch das Patronat über sie hatte. Die Bethlehemskapelle wurde 1622 ebenfalls den Jesuiten übergeben. Nach der Aufhebung des Jesuitenordens und der Entweihung der Kapelle wurde sie 1786 abgerissen. Ihre heutige Gestalt enstand erst zu Beginn der fünfziger Jahre des 20. Jahrhunderts. ${ }^{23}$

In beiden erwähnten Kapellen ließen sich auch einige ehemalige Professoren bestatten, die ihre Alma Mater verlassen hatten und oft wichtige Personen in der Verwaltung der Prager Städte wurden. Auch danach lösten sie jedoch nicht ihre Bande zur Karlsuniversität. Dies zeigte sich übrigens auch in anderen Zusammenhängen. Dennoch überwiegt unter jenen Personen, die die Universität verließen, ihre neue Wirkungsstätte als Bestattungsort.

Einige Professoren, die ihre Tätigkeit an der Karlsuniversität nicht beendet hatten, wurden außer in den erwähnten Kapellen auch in weiteren Prager Kirchen bestattet, beispielsweise in der St.-Heinrichs-Kirche und in der Kirche der Jungfrau Maria vor dem Teyn. Bei Letzterer spielte zweifellos die enge Verbindung der Universität mit dem sogenannten Unteren Konsistorium, an dessen Spitze einige Professoren standen, eine wichtige Rolle. Die bedeutendste in der Teynkirche beigesetzte Person aus diesen Kreisen war Johannes Rokycana, actu regens und zugleich langjähriges Oberhaupt der böhmischen Utraquisten. Mehrere Professoren wurden zu Beginn des 16. Jahrhunderts in der St.-Gallus-Kirche beigesetzt, die in der unmittelbaren Nähe des Karolinums lag. ${ }^{24}$

Der Ort der letzten Ruhestätte konnte auch vom Wunsch des Verstorbenen selbst bestimmt sein - so wünschte sich zum Beispiel Wenzel Zelotýn († 1585), neben seinen Eltern in der Kirche St. Adalbert des Kleineren in Prag-Podskalí bestattet zu werden. ${ }^{25}$ Zuweilen wurde dieser Wunsch aber nicht respektiert - Johannes Chorinnus zum Beispiel wollte auf dem Friedhof bei der Fronleichnamskapelle begraben werden, wurde aber schließlich direkt im Gotteshaus ,ad alios professores“ beigesetzt. ${ }^{26}$

Der Verlauf der Begräbnisse kann am Beispiel des nobilitierten Rektors der Prager Universität Johannes Adami Bystřický dargestellt werden. Er verstarb am 20. Oktober 1602 im Allerheiligenkolleg. Zwei Tage danach fand das Begräbnis statt. Aus einer sehr detailreichen Kostenabrechnung gehen interessante Einzelheiten hervor. So wurde z. B. ein gemaltes Totenschild mit seinem Wappen bestellt. Es wurden ebenfalls Glöckner in acht Altstädter Kirchen sowie in der St.-Wenzelskirche in Prag Neustadt bezahlt. Die Totenbahre wurde offenbar - wie damals üblich - von den Verwaltern der Prager partikularen Lateinschulen getragen, die zur akademischen Gemeinde der Karlsuniversität gehörten. Am eigentlichen

23 Die detaillierteste Bearbeitung der Geschichte der Bethlehemskapelle stellt folgendes Buch dar: Betlémská kaple. O jejich dějinách a zachovaných zbytcích [Die Bethlehemskapelle. Von ihrer Geschichte und den erhaltenen Überresten], Praha 1922 (im Zusammenhang mit dem Thema der vorliegenden Studie vgl. insbesondere František Michálek BaRToš, První stoleti Betléma [Das erste Jahrhundert der Bethlehemskapelle], S. 9-21; Ferdinand HrejsA, Betlém od roku 1516 [Die Bethlehemskapelle ab 1516], S. 22-106). Vgl. ebenfalls Alois KuBIČEK, Betlémská kaple [Die Bethlehemskapelle], Praha 1953. Die Grabsteine hat am gründlichsten B. Ryba behandelt: Ders., Epitafy.

24 Zum Beispiel Michael von Stráž (Jaroslav PorÁk [ed.], Ze starých letopisů českých [Aus den Alten böhmischen Annalen], Praha 1980, S. 340), Wenzel von Patzau (ebd., S. 349), Jakob von Patzau (NB Prag, Sign. XXIII D 217, Fol. 14r), Wenzel Koranda (ebd., Fol. 19v).

25 NB Prag, Sign. XVII G 22a, Fol. 123v. Zu ihm vgl. mit weiteren Hinweisen Enchiridion V, S. 571f.

26 AKU, Sign. Oec. B 14, Fol. 464r, 465r; Ebd., Sign. Oec. B 15, Fol. 328v; Z. Winter, O životě na vysokých školách, S. 207f. 
Begräbnis des verstorbenen Rektors, das am 22. Oktober 1602 in der Fronleichnamskapelle stattfand, nahmen neben den Gliedern der Universität und wahrscheinlich auch den Schülern der örtlichen partikularen Lateinschulen ebenfalls 17 Priester und viele weitere Personen teil. Man kann erwarten, dass unter anderem Vertreter der Prager Stadträte unter ihnen waren. ${ }^{27}$ Diese Zeremonie wurde als eine gewisse antijesuitische Manifestation betrachtet.

Die Societas Jesu wiederum nutzte im Dezember 1622 das prunkvolle Begräbnis des Professors und einstigen Rektors der Karlsuniversität Johannes Campanus, der kurz zuvor zum Katholizismus konvertiert war, zur Demonstration der neuen Verhältnisse nach der Schlacht am Weißen Berg. Auch Campanus fand seine letzte Ruhestätte in der Fronleichnamskapelle.

Bestandteil der Begräbniszeremonie waren ebenfalls Predigten. Daneben erschienen auch weitere, mit dem Tod verbundene tschechische und lateinische Drucke. ${ }^{28}$ Die Verstorbenen sorgten selbst oft bereits in ihren Testamenten dafür, dass an ihrer letzten Ruhestätte ein Grabstein entstand. Das war z. B. bei dem Juristen Johannes Mathias de Sudetis, der sein Testament während der Pestepidemie 1613 niederschrieb, der Fall. Darin wünschte er, auf Kosten der Universität in der Fronleichnamskapelle neben seinem Verwandten, Simon Proxen de Sudetis, bestattet zu werden. Zugleich verfügte er, dass auf seinem Grabstein eine goldene Inschrift angebracht werde, die an seine Auslandsreisen und das universitäre Studium erinnere. Der Text auf der Grabplatte sollte mit den Worten „Academia hoc monumentum antecessori suo posuit" enden. Da er aber damals nicht starb und er zudem die Universität ohne Erlaubnis verlassen hatte, wurde sein Wunsch schließlich nicht erfüllt. ${ }^{29}$

Für das Errichten eines Grabsteins sollte in der Regel die Verwandtschaft oder aber die Universität sorgen. Die meisten der in den Quellen belegten Grabsteine sind jedoch im Zusammenhang mit dem baulichen Wandel, der Aufhebung und dem Abriss der erwähnten Kapellen untergegangen. Einige Grabsteine bzw. ihre Fragmente sind aber dennoch erhalten (vor allem im Lapidarium des Prager Nationalmuseums) oder zumindest aus Skizzen bekannt. ${ }^{30}$ In einigen Fällen entstanden auch Grabplatten außerhalb des Bestattungsortes.

27 Vgl. AKU, Sign. A 51, Fol. 100r; B 14, Fol. 197r-v; Z. WinTer, O životě na vysokých školách, S. 208.

28 Viele von ihnen sind in Enchiridion I-VI sowie unter <www.knihopis.cz $>$ registriert. Vgl. einige Beispiele: Carmina lugubria in obitum ... Thomae Hussinecii ... vita functi 20. Augusti ... 1582, Pragae 1582 (Bibliothek des Prämonstratenserstiftes Strahov, Sign. FK V 1, Nr. 8); Piis Manibus Nobilis et Venerandi Senis D. M. Marci Bydzovini a Florentino etc. civis Novae Urbis Pragensis meritiss. amici desideratiss. qui pié in Christo obiit 15. Sept. Anno 1612, Pragae 1612 (Mährische Landesbibliothek Brünn, Sign. ST2-0024.704, Nr. 68); Piis Manibus ... M. Nicolai de Kamenek ... 15. Decembris anno 1617 vita et professione defuncti, Pragae 1617 (Bibliothek des Nationalmuseums Prag [weiter zitiert als BNM Prag], Sign. 59 D 61, Nr. 64); Samuel MarTiniUs, Kázání pohřebni při poctivém průvodu mrtvého těla ... M. Mikuláše Troila, Pirna 1631 (BNM Prag, Sign. 35 D 9).

29 AKU, Sign. A 17 II, S. 634-639; František Palacký, Poslední vỉle p. Jana Mathiáše ze Sudetu, profesora někdy akademie Pražské [Der letzte Wille des Herrn Johannes Mathias de Sudetis, Professor der einstigen Prager Akademie], Časopis českého musea 2, 1828, S. 115-118; Josef Volf, Jan Matyáš ze Sudetů [Johannes Mathias de Sudetis], Památky archeologické 22, 1906-1908, S. 531-566. Zu Johannes Mathias de Sudetis vgl. zumindest Enchiridion III, S. 294ff.; Lucie Storchova, A Late Humanist Treatise on the Origin of the Bohemians, the Academic Polemics and Their Potential to Perform the Other: De origine bohemorum et Slavorum by Johannes Matthias a Sudetis, Acta Comeniana 22-23/46-47, 2009, S. 149-206.

30 Vgl. z. B. die Marmorgrabplatten aus der Fronleichnamskapelle im sog. Lapidarium des Prager Nationalmuseums (Adam Zalužanský, Ebd., Inv. Nr. H2-38213, Matthaeus Collinus, Inv. Nr. H2-38212). Grabplattenzeichnungen enthält vor allem der vierte Band des Werks Memorabilium Universitatis Pragensis von Thomas Anton Putzlacher von 1768 (AKU, Sign. A 17 IV, S. 835-842). Offensichtlich nach Putzlacher wurden diese Zeichnungen dann in die Chronik des Johann Jeník von Bratřice umgezeichnet (Ders., Pamětihodno všelijakých bývalého slavného ... národu českého se dotýkajicích věcí, 5, BNM Prag, Sign. V D 6/5, S. 693-696, 698-700). Vgl. ebenfalls Z. WINTER, O životě na vysokých školách, S. $210 \mathrm{f}$. 
Die bekannteste ist sicherlich die Platte, die zu Ehren des einstigen Professors und eines der bedeutendsten böhmischen Latinisten des Humanismus, Matthäus Collinus entstand, die nach dessen Tode der Gräzist Jakob Palaeologus († 1585) 1567 im Karolinum anfertigen ließ. Sie wurde mehrmals verlegt, heute befindet sie sich in der Großen Aula des Karolinums. ${ }^{31}$

Der Verstorbenen wurde an der Universität bei verschiedenen Anlässen gedacht, nicht selten auch mehrere Jahrzehnte nach ihrem Tode. Zugleich wurden viele von ihnen auch in literarischen Werken der verschiedensten Art erwähnt - in Chroniken, Annalen, historischen Kalendern, oder aber in spezifischen Schriften wie z. B. jenen vom Typus des Calendarium beneficiorum von Johannes Campanus von Wodnian, eines langjährigen Professors und Rektors der Karlsuniversität. In diesem Werk wurde insbesondere an jene Professoren erinnert, die durch ihr Testament oder auf eine andere Weise der Karlsuniversität einen Teil ihres Besitzes gewidmet hatten. Desgleichen konnte sich die Erinnerung an einen verstorbenen Professor auch in der Bezeichnung der von ihm gegründeten Studienstiftung widerspiegeln, oder es wurde beispielsweise bei der Ernennung einzelner Stipendiaten an ihn erinnert. ${ }^{32}$

Abschließend seien einige zusammenfassende Bemerkungen erlaubt. Wenngleich die Quellen zum Thema Sterben, Tod und Bestattung von Professoren der Prager Universität vom 15. bis 17. Jahrhundert nur sehr bruchstückhaft überliefert sind, ermöglichen sie es trotzdem, viele diesbezügliche Zusammenhänge zu verfolgen. Die Bearbeitung dieser Problematik, die in der bisherigen Forschung vernachlässigt wurde, kann einige neue Perspektiven aufdecken, nicht nur im Zusammenhang mit dem täglichen Leben der Universität selbst, sondern auch mit der materiellen sowie der spirituellen Kultur der Prager Städte im Spätmittelalter und in der frühen Neuzeit.

Die genannten Quellen zeigen eindeutig, welche Rolle der Tod in der individuellen wie kollektiven Erinnerung spielte sowie das Streben nach Erfüllung des durch spätmittelalterliche und frühneuzeitliche artes moriendi geprägten Ideals. Dies trat mit gewissen Abweichungen in allen konfessionellen Milieus zu Tage. Obwohl der Status der actu regentes der Prager Universität in der Zeit nach dem Hussitentum, der Zeit der Jagiellonenherrscher und vor der Schlacht am Weißen Berg (1620) nicht besonders großartig und bestimmt nicht mit jenem der Eliten der Ständegesellschaft vergleichbar war, kann man dennoch anhand des Ablaufs ihrer Begräbnisse die bedeutende Rolle sehen, die die Karlsuniversität in Prag und in den böhmischen Ländern, insbesondere in Bezug auf das städtische Milieu, spielte. Zugleich zeigen sie die enge Verknüpfung der Universität mit der utraquistischen Kirchenverwaltung, in der viele der betrachteten Professoren zentrale Posten innehatten.

Mit einer gewissermaßen neuen Situation musste sich die Universität nach dem Erlass des Majestätsbriefes Rudolfs II. über die Religionsfreiheit (1609) auseinandersetzen, ${ }^{33}$ als

31 Silva Dobalová, Pamětní deska Matouše Collina z Chotěřiny: poznámky kjejí ikonografii [Die Gedenktafel des Matthäus Collinus von Choteřina: Notitzen zu ihrer Ikonografie], Epigraphica \& Sepulcralia 3, 2011, S. 41-54.

32 Ioannes Campanus, Academiae Pragensi collatorum, strenae loco, ineunte Anno 1616 missum generoso et strenuo equiti domino Udalrico Gerdorfio a Gerdorf et Malsvicz etc., Pragae typis Ionathae Bohutsky de Hranicz 1616 (zugänglich unter<books.google.cz>); Karel Hrdina (ed.), Mistr Jan Kampanus, Mecenáši Karlovy university [Magister Johannes Campanus, Mäzene der Karlsuniversität], Praha 1949; Josef PoLIŠEnskÝ - Jana Vobrátilová, M. Jana Kampana Kalendář dobrodiní, prokázaných pražské akademii [Des Magisters Johannes Campanus Kalender der Prager Universität erwiesener Wohltaten], AUC-HUCP 4/1, 1963, S. 67-95.

33 Vgl. mit weiteren Quellen- und Literaturhinweisen Martin HoLÝ, Vereitelte Hoffnungen? Der rudolfinische Majestätsbrief und das nichtkatholische höhere Schulwesen in Böhmen, in: Jaroslava Hausenblasová - Jiří 
sie zwar einerseits zum Teil reformiert wurde und die Anzahl der Professoren stieg, andererseits aber völlig unter die Vormundschaft ständischer Politiker geriet. Diese Unterordnung unter die Stände äußerte sich unter anderem im Bereich der Literatur, beispielsweise in dem Bestreben, durch den Verweis auf Persönlichkeiten, die sich in der Vergangenheit um die Entwicklung der Universität verdient gemacht hatten, in den Reihen der Stände neue Mäzene zu gewinnen und dergleichen mehr. Einen grundlegenden Wendepunkt, auch in Bezug auf das untersuchte Thema, bedeutete die Niederschlagung des Ständeaufstands in der Schlacht am Weißen Berg (1620) und ihre Folgen, insbesondere die Übergabe der Universität in die Hände der Jesuiten und ihre vollständige Rekatholisierung. ${ }^{34}$

(Sprachliche Korrektur: Wolf B. Oerter)

\title{
Finanzielle Förderung:
}

Der Aufsatz entstand im Rahmen des Projekts Nr. GA18-00408S „Universitas magistrorum. Professoren der Prager utraquistischen Universität (1458-1622)“ der Tschechischen Agentur zur Förderung der wissenschaftlichen Forschung (Grantová agentura České republiky).

\section{MEZI REALITOU A MÝTEM. SMRT A POHŘBY PROFESORU゚ PRAŽSKÉ UNIVERZITY OD 15. DO POČÁTKU 17. STOLETÍ}

\author{
RESUMÉ
}

Ačkoli prameny k problematice umírání, smrti a pohřbů profesorů pražské univerzity v 15 . až raném 17. století jsou dochovány poněkud torzovitě, umožňují přesto sledovat řadu souvislostí této problematiky. Studie přitom vychází jak z pramenů úřední provenience, tak z některých egodokumentů, pramenů literárních, ikonografických i dalších (z hmotných památek). Ovšem úroveň znalostí o přibližně 200 osobách, které ve zkoumané době působily na pražské univerzitě jako její profesoři (magistri actu regentes), je značně kolísavá. O řadě z nich máme ve vztahu $\mathrm{k}$ tématu pouze omezené množství informací.

Studie sleduje okolnosti smrti pražských profesorů (kdy, kde a proč zemřeli), přičemž se detailně zaměřuje zejména na průběh vlastních pohřebních obřadů a konkrétní místo jejich posledního odpočinku. To záviselo na celé řadě faktorů, kromě jiného i na přání zesnulých, které mohlo být vyjádřeno také v jejich závěti. Jako nejčastější místa posledního odpočinku se již ve středověku prosadila především dvě místa, a to kaple Božího Těla na Novém Městě pražském a Betlémská kaple na Starém Městě pražském. Oba tyto svatostánky byly již od středověku úzce spojeny s dějinami Karlova obecného učení.

V prŕípadě kaple Corporis Christi, která byla podobně jako Betlém zrušena a zbořena za josefínských reforem v 18. století, bylo možné sledovat kromě jiných témat (náhrobky) také tradici zpívaných vigilií za duše dobrodinců univerzity, včetně někdejších profesorů, jež jsou pramenně doloženy již od 60. let 15. století a pokračovaly

Mikulec - Martina Thomsen (Hgg.), Religion und Politik im frühneuzeitlichen Böhmen. Der Majestätsbrief Kaiser Rudolfs II. von 1609, Stuttgart 2014, S. 171-180, hier S. 171f., 174-177.

34 Zur Situation der Karlsuniversität nach der Schlacht am Weißen Berg vgl. bis heute am ausführlichsten Z. WiNTER, Děje vysokých škol, S. 162-216. Vgl. ebenfalls Wenzel Wladiwoj Tомек, Geschichte der Prager Universität, Prag 1849, S. 243-254; F. KAVKA - J. PetRÁŇ (eds.), A History of Charles University, I, S. 263-297 (Autorin des Kapitels „The Administrative and Institutional Development of Prague University“ ist Ivana ČonNEJovÁ). 
i v následujícím věku. Upozorněno bylo také na některé další aspekty související s budováním univerzitní paměti, memoriální kultury, zejména připomínání zesnulých „,dobrodinců“ v podobě náhrobků, různých odkazů apod. Závěr přináší několik shrnujících poznámek, včetně postižení základních vývojových trendů, stejně jako zdůraznění výrazného přelomu, který i ve vztahu k předmětu studie znamenal rok 1622 (předání univerzity jezuitům).

doc. PhDr. Mlada Holá, Ph.D.

Filozofická fakulta UK, Praha

mlastep@seznam.cz

prof. PhDr. Martin Holý, Ph.D.

Historický ústav AV ČR, a Filozofická fakulta UJEP, Ústí nad Labem.

holy@hiu.cas.cz 


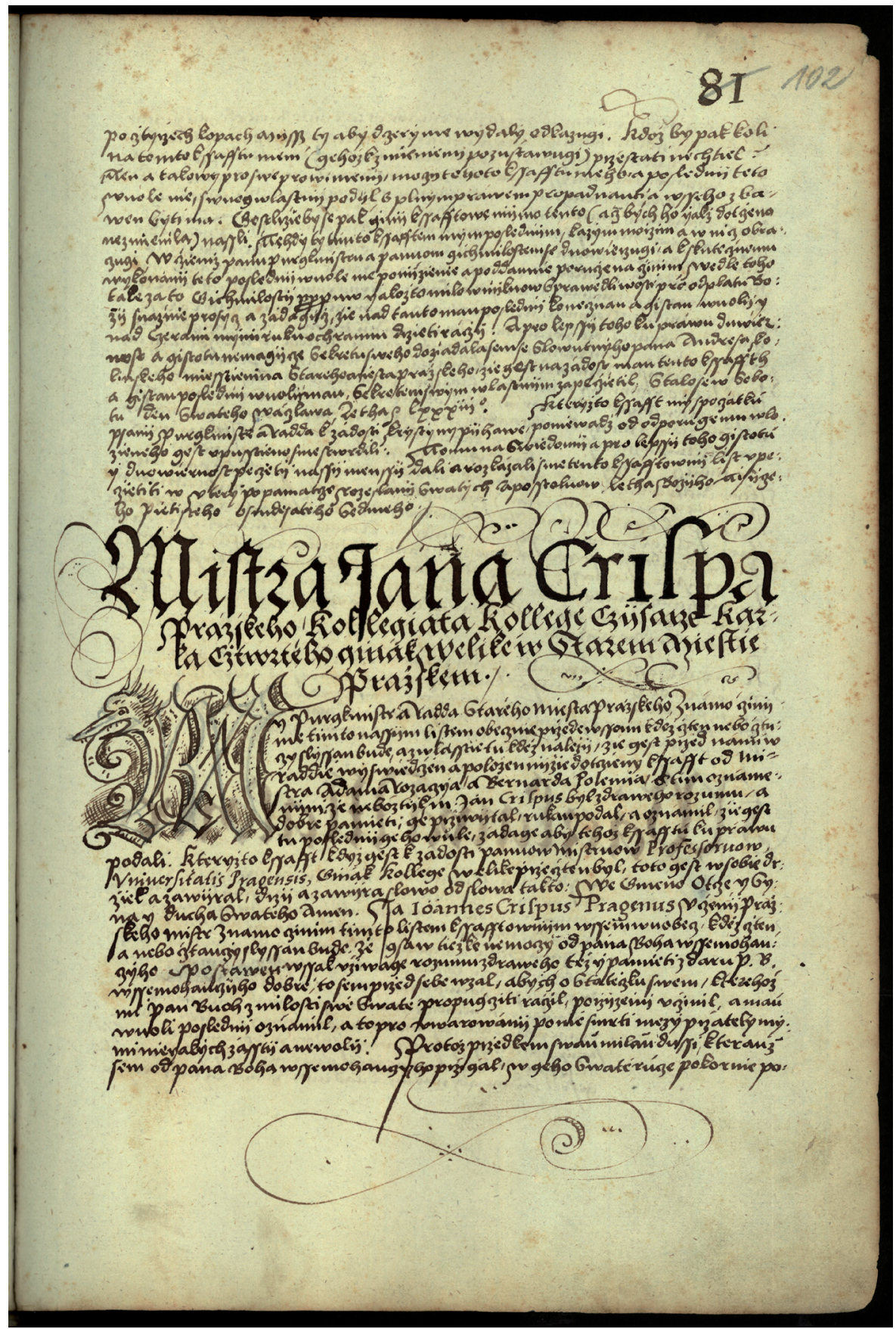




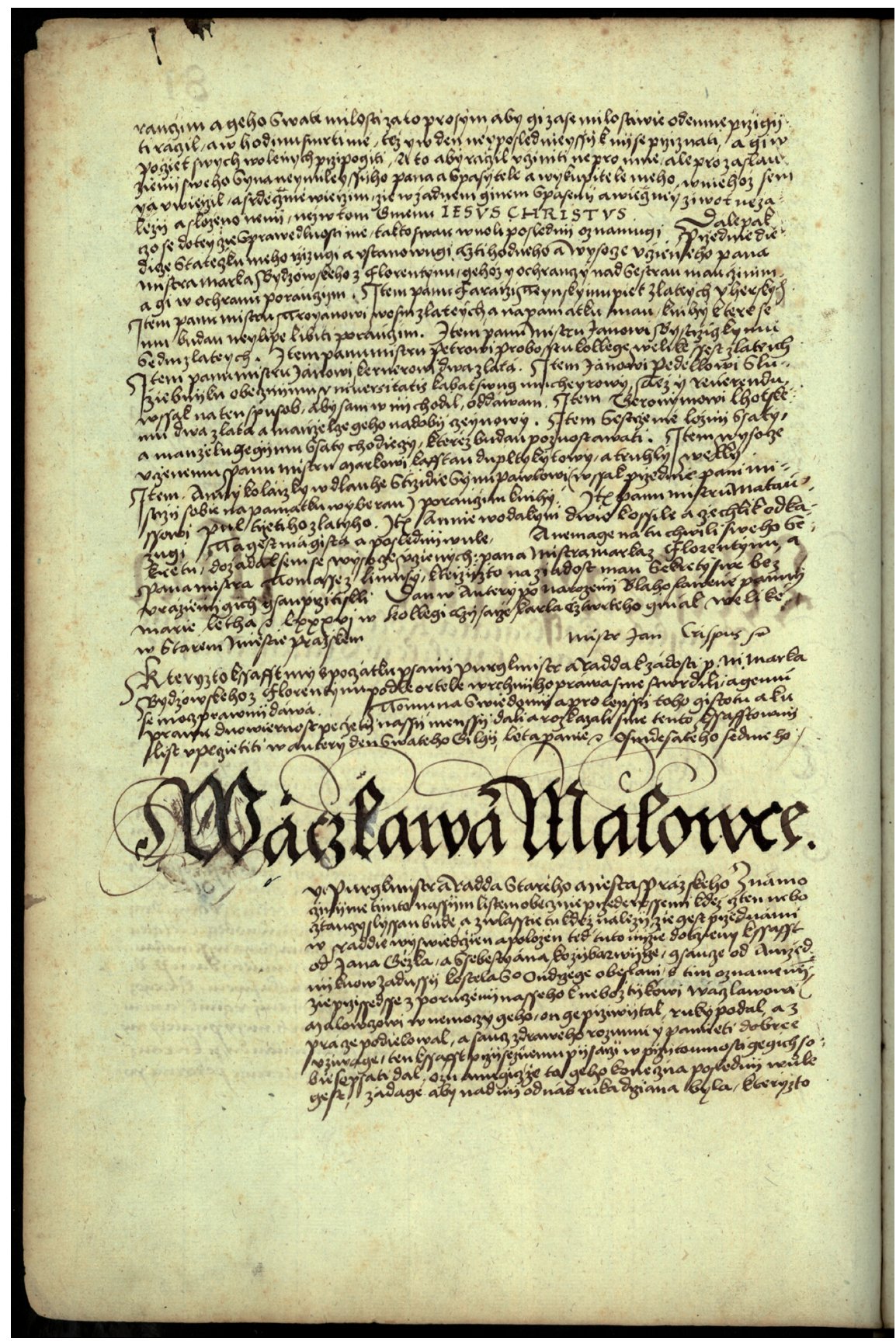

Testament von Johannes Crispus, gebürtig aus Prag, seit 1584 Professor der Prager Universität, gestorben schon am 10. September 1586 (Archiv der Stadt Prag, ms. 2205,

Fol. 81r-v) 


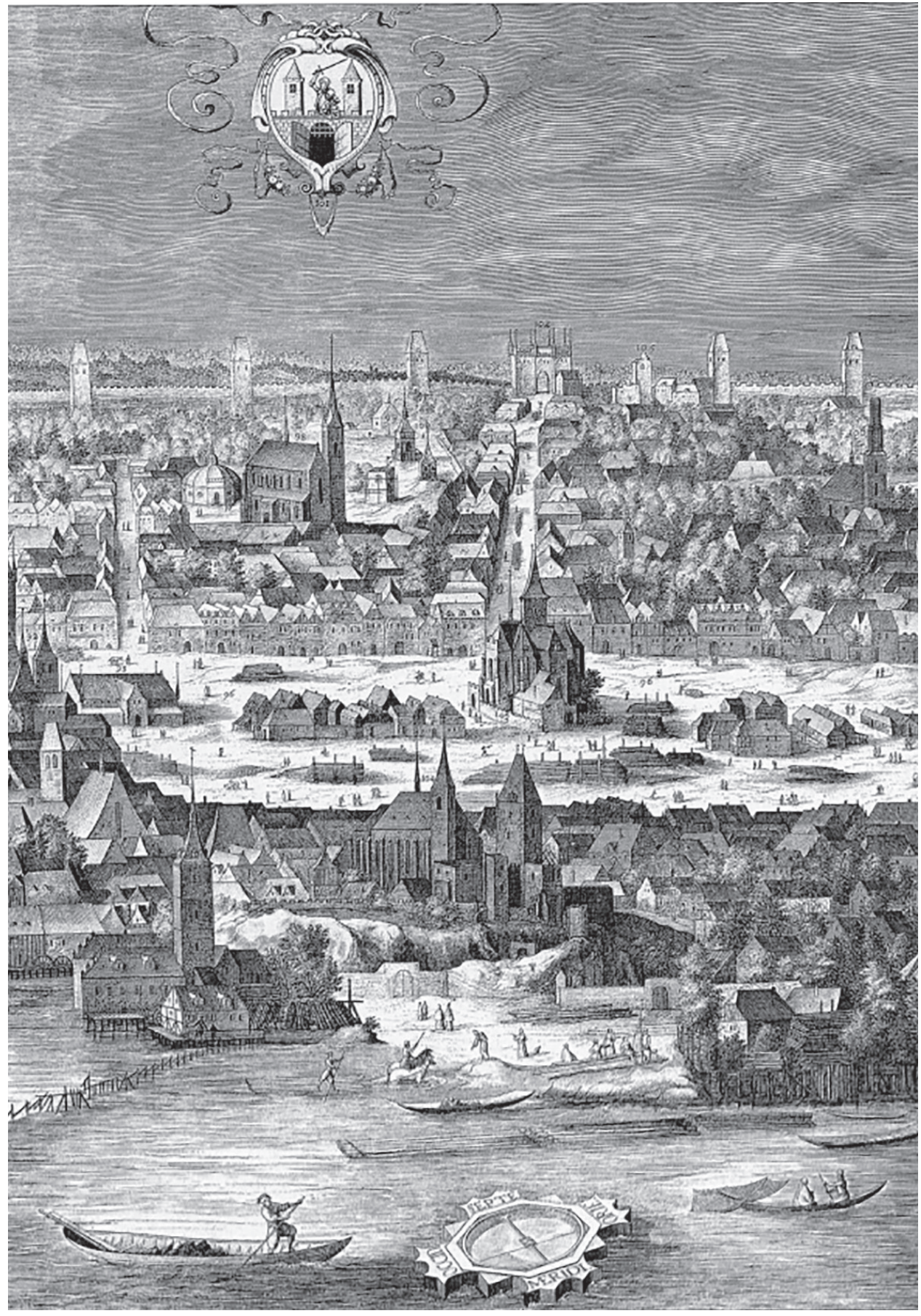

Fronleichnamskapelle am Viehmarkt, Ausschnitt aus Sadelers Prospekt von Prag (1606) 
Gys.

R.VIR MUMARCUS RYDZOVINUS IFLORENTINO COLLEII REGIS

VENCESLAI IN VET: URTE PREPUSIXUS ET RECTOE UNTVERS: PRAGENSIS, ANI" MA COELO RED: CORPUSHIC SEPELIRI. CBBIIT/SSEPT:AN:;bie

Me bét ALMA FIDES.

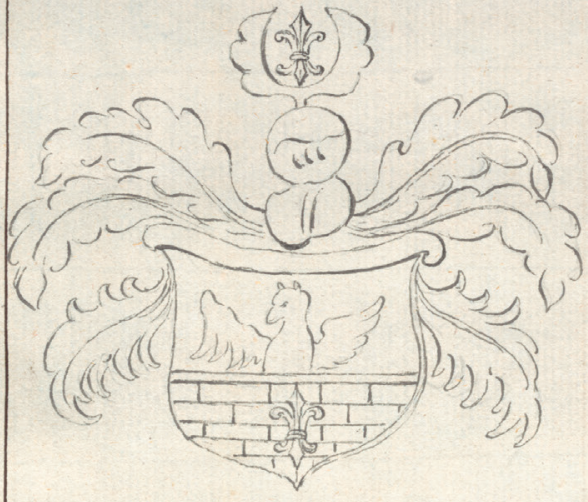

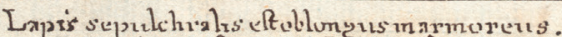

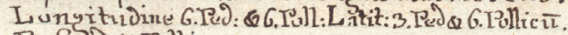
Profirid: \%. Pollicum.

\section{A}

CLVTR M.TEOJANUS NIGELLUS AOSKORZINA HERMANINESTICENUSACA DEMILE PRAGENSIS PRO FF SSOR,TEREVE RECTOH MORITUR INAUGUST:A : $i 6 \mathrm{c}$

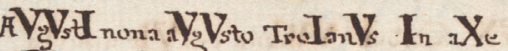

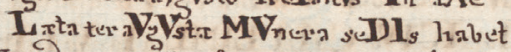
Harc Jemum vitic ef, quam vixurat arte Laboner Plena srouyere yonvis punderevita fuiz,

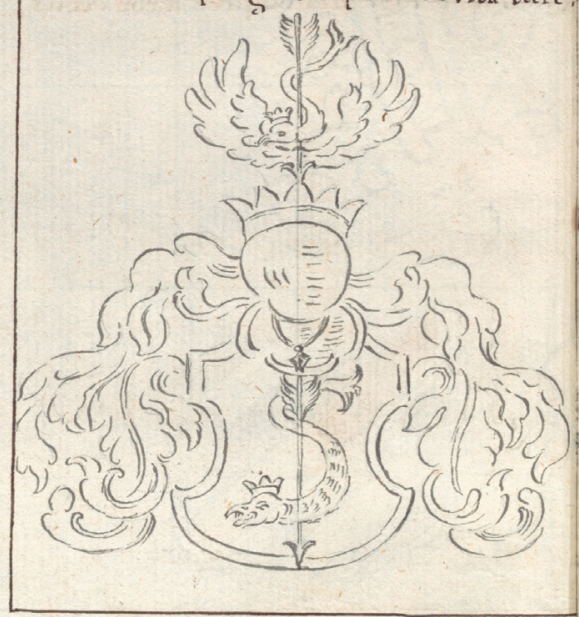

Lapis eff oblumgus marmuris unleescentis lune

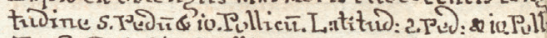
Profinditatis G.Pullicum.

Eine Zeichnung des Grabsteins von Mag. Troianus Nigellus (Johann Jeník von Bratřice, Pamětihodno všelijakých bývalého slavného ... národu českého se dotýkajících věcí, 5, BNM Prag, Sign. V D 6/5, S. 695) 